Ambiente \& Água - An Interdisciplinary Journal of Applied Science
ISSN 1980-993X - doi:10.4136/1980-993X
www.ambi-agua.net
E-mail: ambi-agua@agro.unitau.br

\title{
Eventos extremos de precipitação em Belém-PA: uma revisão de notícias históricas de jornais
}

\author{
doi: 10.4136/ambi-agua.1433
}

Received: 19 Jun. 2014; Accepted: 03 Nov. 2014

\section{Thamiris Luisa de Oliveira Brandão Campos ${ }^{1}$; Maria Aurora Santos da Mota²; Sergio Rodrigo Quadros dos Santos ${ }^{1}$}

\author{
${ }^{1}$ Instituto Nacional de Pesquisas Espaciais (INPE), São José dos Campos, SP, Brasil \\ ${ }^{2}$ Universidade Federal do Pará (UFPA), Belém, PA, Brasil \\ *Autor correspondente: e-mail: brandao.thamiris@gmail.com, \\ aurora_ufpa@yahoo.com.br, sergiosanntos@yahoo.com.br
}

\section{RESUMO}

Os impactos socioeconômicos dos Eventos Extremos de Precipitação Diária em Belém-Pará foram estudados com base em histórias relatadas nas notícias dos jornais da cidade durante o período de 1987 a 2009. Estes eventos foram caracterizados como extremos por meio da Técnica do Decil. O objetivo foi identificar as consequências e os principais bairros afetados pelos eventos extremos de precipitação diária. Os anos que estiveram sob influência do fenômeno El Niño (La Niña) foram os que apresentaram menor (maior) frequência de Eventos Extremos de Precipitação e de noticias publicadas nos jornais da cidade. A variação mensal mostrou que os Eventos Extremos e as notícias dos jornais foram maiores no período "mais chuvoso" (verão/outono austral). As histórias relatadas nas notícias dos jornais da cidade indicaram que o alagamento das ruas é a principal consequência dos eventos extremos para a cidade de Belém-Pará e os bairros mais afetados são Cremação, Jurunas e Batista Campos. Esses bairros são vizinhos e tem como fator comum a presença da bacia hidrográfica da Travessa Quintino Bocaiúva, a qual apresenta baixa declividade e dificulta o escoamento da água, favorecendo a formação de pontos de alagamentos. Identificou-se que a falta de infraestrutura da cidade é o fator predominante quanto à consequência dos eventos extremos de precipitação diária.

Palavras-chave: cidade, eventos extremos, jornal, precipitação diária.

\section{Extreme precipitation events in Belém-Pará: a historical review of newspaper articles}

\begin{abstract}
This study examined the socioeconomic impacts of Daily Extreme Precipitation Events (hereafter "DEPEs") in Belem-Pará during the period 1987-2009. The DEPEs were characterized as "extreme" using the Decile technique. The objective of the study was to identify the consequences and the main neighborhoods affected by these events. The years influenced by occurrences of El Niño or La Niña had the lowest or the highest rates of DEPEs, respectively, and as well as the number of articles published in the city's newspapers. The monthly variation showed that the DEPEs and resulting newspaper articles were higher in
\end{abstract}


the "wettest" (summer / austral autumn) period. The newspaper articles indicated that street flooding is the main consequence of DEPEs in the city of Belém-Pará, and that the most affected districts are Cremação, Jurunas and Batista Campos. These neighborhoods are near to one another and are all located in the Travessa Quintino Bocaiúva watershed, which has a low slope that delays the flow of water, favoring flooding. The city's lack of infrastructure is the main reason for the severe consequences of DEPEs.

Keywords: city, daily precipitation, extreme events, newspapers.

\section{INTRODUÇÃO}

Valores discrepantes de um estado climático médio (doravante chamado de "eventos extremos") ocorrem em escalas temporais que variam de dias a milênios, embora os mais importantes para as atividades humanas sejam os eventos extremos de curta duração (no máximo alguns minutos ou poucas horas), os quais cobrem uma área horizontal de centenas a poucos metros. Incluem-se nessa escala as tempestades convectivas, rajadas de ventos, tornados, chuvas torrenciais, granizo e ocorrência de descargas atmosféricas (Malone, 1951; Marengo, 2009).

A intensidade dos eventos extremos de precipitação tem aumentado ao redor do mundo, preocupando tanto a comunidade científica quanto as autoridades, por causarem intensos danos à sociedade assim como ao ecossistema. Bryan et al. (2009) identificaram que as tendências demográficas deve ser uma questão a ser abordada nos debates políticos, o autor destaca que o rápido crescimento populacional agrava os efeitos das mudanças climáticas ou impede a capacidade adaptação. Pode ser notado que as consequências dos eventos extremos de precipitação têm chamado atenção, haja visto que em distintas regiões do planeta ocorrem prejuízos como danos à infraestrutura das cidades, agricultura, turismo, além de perdas de bens materiais e de vidas humanas.

Os Sistemas Meteorológicos e Mecanismos de Interações Oceano-Atmosfera influenciam nas ocorrências e intensificação dos eventos extremos, como por exemplo, os sistemas de meso (Linhas de Instabilidade) e de grande escala (Zona de Convergência Intertropical, Oscilação de Madden Julian, Padrão de Dipolo no Oceano Atlântico, El Niño-Oscilação Sul/ENOS), que de acordo com a atividade/fase agem ora acelerando ora enfraquecendo o desenvolvimento das nuvens e consequentemente a quantidade de chuva, ocasionando grandes inundações ou secas prolongadas em diferentes partes do planeta (Chu et al., 2009; Truong et al., 2009).

A cidade de Belém, capital do Estado do Pará, localizada na região Amazônica (Zona Equatorial) possui uma homogeneidade espacial e sazonal de temperatura, o que não acontece em relação à pluviosidade, pois sofre influência dos sistemas meteorológicos de meso e grande escalas mencionados anteriormente. Com precipitação média anual de 3000 $\mathrm{mm}$, precipitações diárias maiores que $25 \mathrm{~mm}$ são comuns na cidade e causam grandes prejuízos e transtornos para sociedade, como alagamentos e falta de energia elétrica. Neste contexto, o objetivo do presente estudo é identificar as consequências e os principais bairros afetados pelos eventos extremos de precipitação diária. Além de mostrar que veículos de comunicação, como os jornais, podem ser uma importante ferramenta para este tipo de análise histórica que identifica os desastres físicos, econômicos e sociais que a população enfrenta por conta das chuvas.

\section{MATERIAL E MÉTODOS}

A cidade de Belém-PA (Figura 1) está situada na Zona Equatorial ( $1^{\circ} 28^{\prime} \mathrm{S}$ e $\left.48^{\circ} 29^{\prime} \mathrm{W}\right)$. A baía do Marajó a banha ao norte, a leste é delimitada pelos municípios de Benevides e 
Ananindeua, o rio Guamá é o seu limite ao sul e as baías do Guajará e do Marajó limitam a cidade a oeste (Silva, 2008). O clima da cidade é tropical chuvoso de monção (segundo a classificação de Köppen (1900-1936)), com média anual da temperatura do ar de 26,0 $0^{\circ} \mathrm{C}$, com máximas e mínimas variando de 31,5 a $22,0^{\circ} \mathrm{C}$ respectivamente (INMET, 1992) e o acumulado anual de precipitação varia de $2500 \mathrm{~mm}$ a $3900 \mathrm{~mm}$ (resultado será mostrado na seção 3.1).

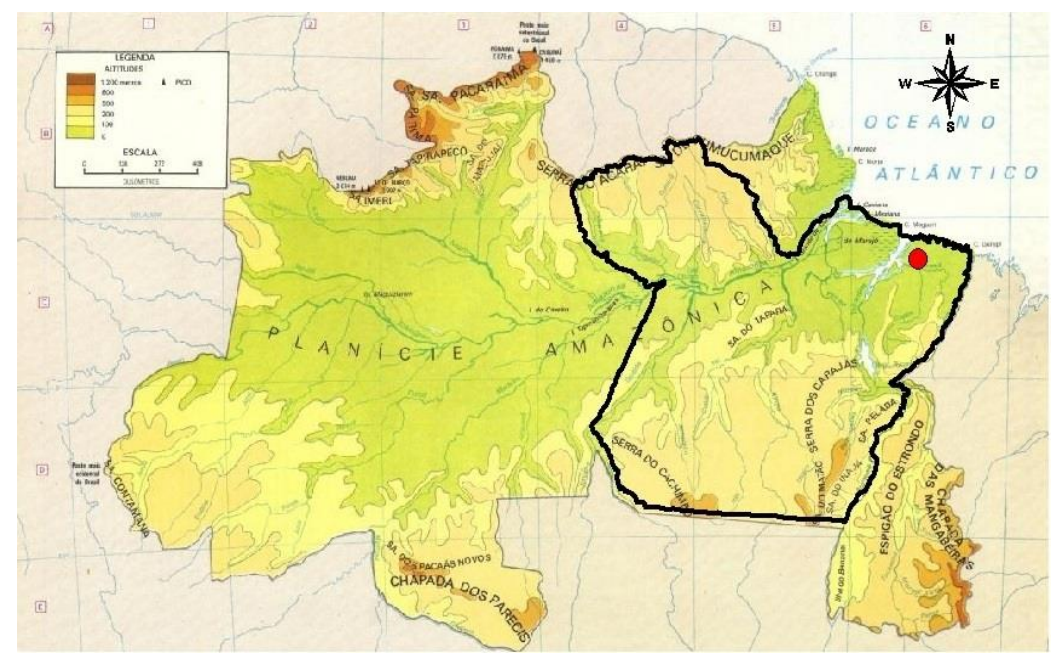

Figura 1. Região da Amazônia brasileira. O ponto em vermelho sinaliza a cidade de Belém - Pará. Figura adaptada de Simielli (1991).

Neste estudo foram utilizados dados pluviométricos, coletados nas estações climatológicas da Empresa Brasileira de Pesquisa Agropecuária (EMBRAPA- Amazônia Oriental), no período de 1987 a 2005, e do Instituto Nacional de Meteorologia (INMET) nos anos de 2006 a 2009. Estes dados são de precipitações acumuladas de 24 horas, observações feitas todo o dia às 1200 UTC (09h00 horas local). O índice do Niño Oceânico (INO) do "Climate Prediction Center" da "National Oceanic and Atmospheric Administratation (NOAA), disponível no site http://www.cpc.ncep.noaa.gov/products/analysis_monitoring/ ensostuff/ensoyears.shtml, foi utilizado para comparação das fases do ENOS com a variabilidade interanual da precipitação e dos eventos extremos de precipitação diária (EEPD). Este índice define as fases com base na anomalia da temperatura da superfície do mar (TSM) em intensidade fraca (anomalia de TSM de $0,5^{\circ} \mathrm{C}$ a $0,9^{\circ} \mathrm{C}$ ), moderada $\left(1,0^{\circ} \mathrm{C}\right.$ a $\left.1,4^{\circ} \mathrm{C}\right)$ e forte $\left(\geq 1.5^{\circ} \mathrm{C}\right)$.

As notícias dos principais jornais sobre as chuvas que afetaram a cidade e/ou sociedade foram obtidas no Arquivo Público, Biblioteca Arthur Vianna, da Fundação Cultural do Pará Tancredo Neves (CENTUR) e nos jornais online. Para efeito da pesquisa nos jornais foram consideradas que todas as precipitações maiores que $20 \mathrm{~mm}$, no período de 1987 a 2009 , poderiam causar impactos a cidade de Belém-Pará. Este limiar foi usado antes da determinação estatística de eventos extremos de precipitação diária (EEPD) para colher o máximo das notícias, possíveis, nos jornais e assim avaliar o impacto das chuvas desde a intensidade moderada. Importante ressaltar que as 296 notícias que foram catalogadas neste período estão disponíveis fisicamente para pesquisa no prédio da Meteorologia na Universidade Federal do Pará.

A detecção dos efeitos negativos que os eventos extremos de precipitação de curto prazo podem gerar a uma cidade é bastante importante para a mitigação destes transtornos e as notícias de jornais tem se mostrado um método respeitável para análise, pois abordam e exibem as consequências que os eventos extremos de precipitação tenham acarretado a 
diversas cidades e/ou sociedades. Desta maneira, as notícias foram catalogadas a partir de caracterização dos bairros afetados e dos tipos de problemas causados à população devido à ocorrência das chuvas, tais como: alagamentos, congestionamento no trânsito, queda de árvores, destelhamentos de casas e interrupção de energia elétrica.

A técnica de Decil, conforme proposto por Xavier et al. (2007), foi aplicada a série de dados diários de chuva (1 de janeiro de 1987 a 31 de dezembro de 2009), para definir os eventos extremos de precipitação diária (EEPD). Este método consiste em dividir a série, organizada em ordem crescente, em dez partes iguais $(10 \%, 20 \%, \ldots, 90 \%)$, considerando o nono Decil como precipitação extrema, aqueles que, embora sejam em número muito reduzido, correspondem a $10 \%$ do total de chuva de toda a série. Os decis foram calculados da seguinte maneira (1):

$$
D_{k}=l_{i}+\frac{\left[\left(\frac{k \sum f_{i}}{10}\right)-f_{a n t}\right]}{f_{i}} \times h
$$

em que:

$$
\begin{aligned}
& \text { Dk = é o Decil que se pretende calcular, } \\
& \mathrm{li}=\text { é o limite inferior da classe, } \\
& \mathrm{k}=\text { é o número de ordem do Decil, } \\
& \mathrm{fi}=\text { é a frequência da classe da posição do Decil, } \\
& \text { fant = é a frequência da classe anterior do Decil e } \\
& \mathrm{h}=\text { é a amplitude da distribuição }
\end{aligned}
$$

Os eventos extremos de precipitação diária (EEPD) foram considerados precipitações maiores ou iguais a $24 \mathrm{~mm}$, valor correspondente ao nono Decil da série. Após a caracterização dos EEPD, calculou-se o coeficiente de determinação $\left(\mathrm{R}^{2}\right)$ entre a série de EEPD (frequência do acumulado mensal de EEPD, independente se houve notícia ou não) com as notícias dos jornais (considerando o limiar inicial de $20 \mathrm{~mm}$ ). Para verificar se a ocorrência de EEPD gera impacto a cidade de Belém, com publicação de notícias de chuva a partir de $20 \mathrm{~mm}$.

$\mathrm{O} \mathrm{R}^{2}$ é um indicador usado para medir a qualidade do ajustamento de uma linha de regressão, isto é, em que proporções a variável dependente (y) é explicada pela variável independente (x). Seu valor está no intervalo de 0 a 1 , se $\mathrm{R}^{2}$ for igual a 1 , isto significa que todos os pontos observados se situam "exatamente" sobre a reta de regressão. Tendo-se, neste caso, um ajuste perfeito. As variações da variável Y são 100\% explicadas pelas variações da variável $\mathrm{X}$, não ocorrendo desvios em torno da função estimada. Por outro lado, se $\mathrm{R}^{2}=0$, isto quer dizer que as variações de $\mathrm{Y}$ são exclusivamente aleatórias e explicadas pelas variações de outros fatores que não $X$. Mais detalhes sobre o coeficiente de determinação podem ser obtidos em Wilks (2006).

\section{RESULTADOS E DISCUSSÃO}

\subsection{Análise interanual e mensal da precipitação e dos EEPD em Belém-Pará para os anos de 1987 a 2009}

A Figura 2 apresenta a variabilidade interanual do acumulado da precipitação e da frequência dos EEPD durante os anos de 1987 a 2009. O acumulado anual de precipitação variou de $2500 \mathrm{~mm}$ a $3900 \mathrm{~mm}$ e a frequência dos EEPD foi de 22 a 54 eventos por ano. Os 
anos que apresentaram maiores acumulados de precipitações foram em 1989 com $3.890 \mathrm{~mm}$ de chuva (54 eventos de EEPD), 1988 com 3.697,7 mm (49 eventos de EEPD) e 2006 apresentou 3.663,8 mm (51 eventos de EEPD). Excetuando o ano de 2006 que foi um ano neutro, os anos de 1989 e 1988 estiveram sob influência do fenômeno La Niña que aumenta as chuvas na cidade de Belém. Os menores volumes de precipitações e de EEPD ocorreram nos anos de 1991 com 2513,3 mm (30 eventos de EEPD), 1997 com 2528,4 mm (35 EEPD) e 1990 com 2528,9 mm (22 eventos de EEPD). Excetuando o ano de 1990, que foi um ano neutro, os anos de 1991 e 1997 estiveram sob a influência do fenômeno El Niño que inibe as chuvas na cidade de Belém. Estes resultados corroboram com Marengo e Nobre (2000) que observaram o episódio de El Niño 1997/98 o mais intenso dos últimos 118 anos e as condições mais úmidas foram encontradas durante o episódio de La Niña 1988/89.

Embora o ENOS tenha um papel importante na interação entre a TSM e a precipitação da Amazônia, ele não é o único modulador da precipitação nesta região, por isso que nem todos os eventos de maiores/menores precipitações estão associados a este padrão. Os eventos ocorridos em 2006 e 1990 estiveram entre os três anos de maiores e menores volumes de precipitação anuais, porém o fenômeno ENOS estava em neutralidade, indicando que existiu influência de outro padrão para a variação acentuada da precipitação nestes anos. Souza e Nobre (1998) sugerem que a TSM do Oceano Atlântico interfere na ocorrência das chuvas na Amazônia, onde o gradiente térmico meridional e inter-hemisférico sobre o Atlântico Equatorial exerce influência no deslocamento norte-sul da Zona de Convergência Intertropical (ZCIT), que constitui o principal sistema meteorológico indutor de chuvas no nordeste da Amazônia. Grimm (2011) indica que o impacto do ENSO na chuva do nordeste da América do sul é mais forte se as anomalias de TSM tiverem o mesmo sinal no Pacifico Tropical leste e no Atlântico Tropical norte, devido ao efeito direto da relação ENSO via anomalias atmosféricas.

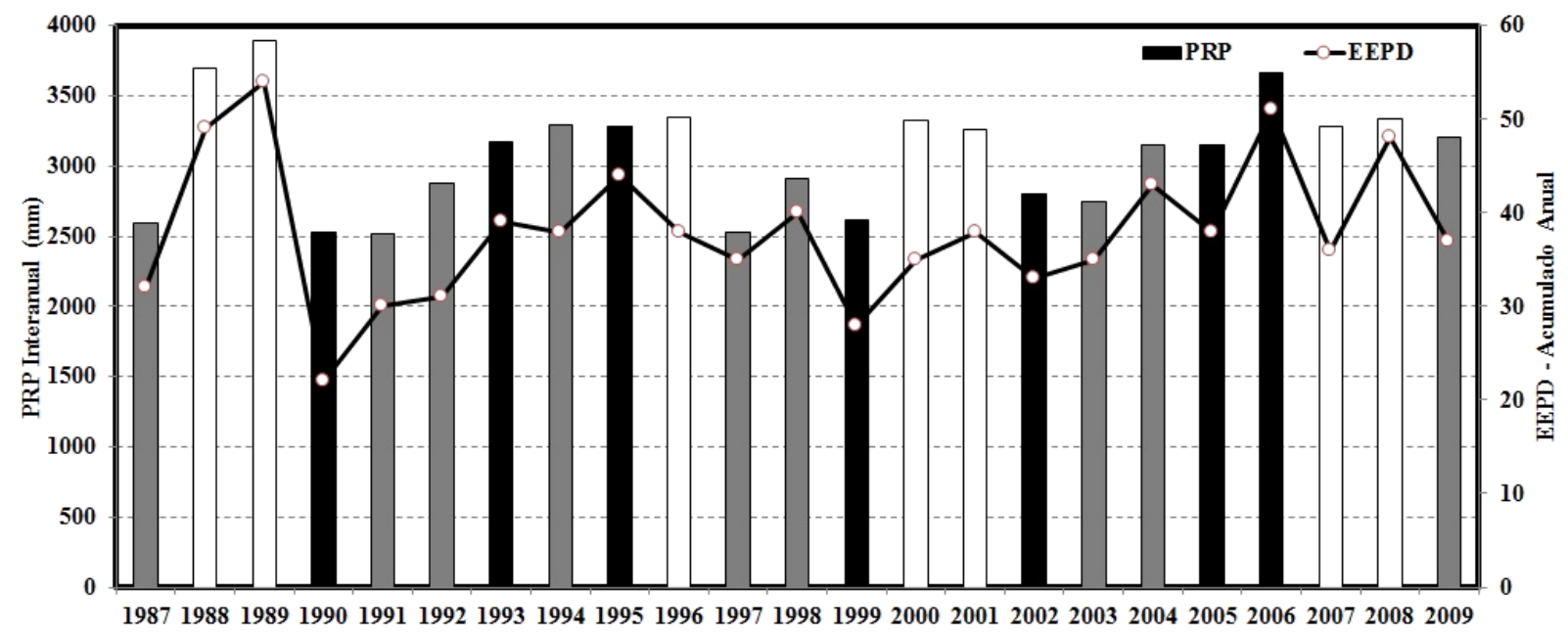

Figura 2. Variabilidade interanual da precipitação (barras) e da frequência dos EEPD (linha) em Belém para 1987 - 2009. As barras na cor cinza representam os anos que estiveram sob a influência do fenômeno El Niño, as barras em branco estiveram sob a influência do fenômeno La Niña e as pretas foram anos que não estiveram sob a influência do ENOS.

Analisando a precipitação média mensal em $\mathrm{mm} \mathrm{dia}^{-1}$ e número de casos mensais de EEPD no período de 1987-2009 (Figura 3) é possível observar que nos meses de dezembro a maio, período "mais chuvoso" da Região, ocorreu uma média mensal de 12,2 $\mathrm{mm} \mathrm{dia}^{-1}$ de precipitação (71,9\% do total da média mensal) e 693 EEPD (79,3\% do total). Os meses com maior precipitação foram março e abril, a média mensal desses dois meses foi de 14,6 mm $\operatorname{dia}^{-1}$ de chuva (28,6\% do total da média mensal). Enquanto que no período "menos chuvoso" 
(junho a novembro) a média mensal foi de $4,8 \mathrm{~mm} \mathrm{dia}^{-1}$, o que representou $28,1 \%$ do total da média mensal, com 181 EEPD (20,7\% do total).

A variabilidade da precipitação entre os dois períodos (chuvoso e menos chuvoso) mostra a influência dos fenômenos de meso e grande escala no aumento e na redução de precipitação e consequentemente nos EEPD. O volume de precipitação e a quantidade elevada de EEPD, no período chuvoso, estão relacionados ao período de atuação da ZCIT e da MJO na região (Grimm, 2011; De Souza e Ambrizzi, 2006). Enquanto que no período menos chuvoso, as Linhas de Instabilidade são responsáveis por cerca de $45 \%$ da ocorrência das chuvas (Cohen et al., 1995).

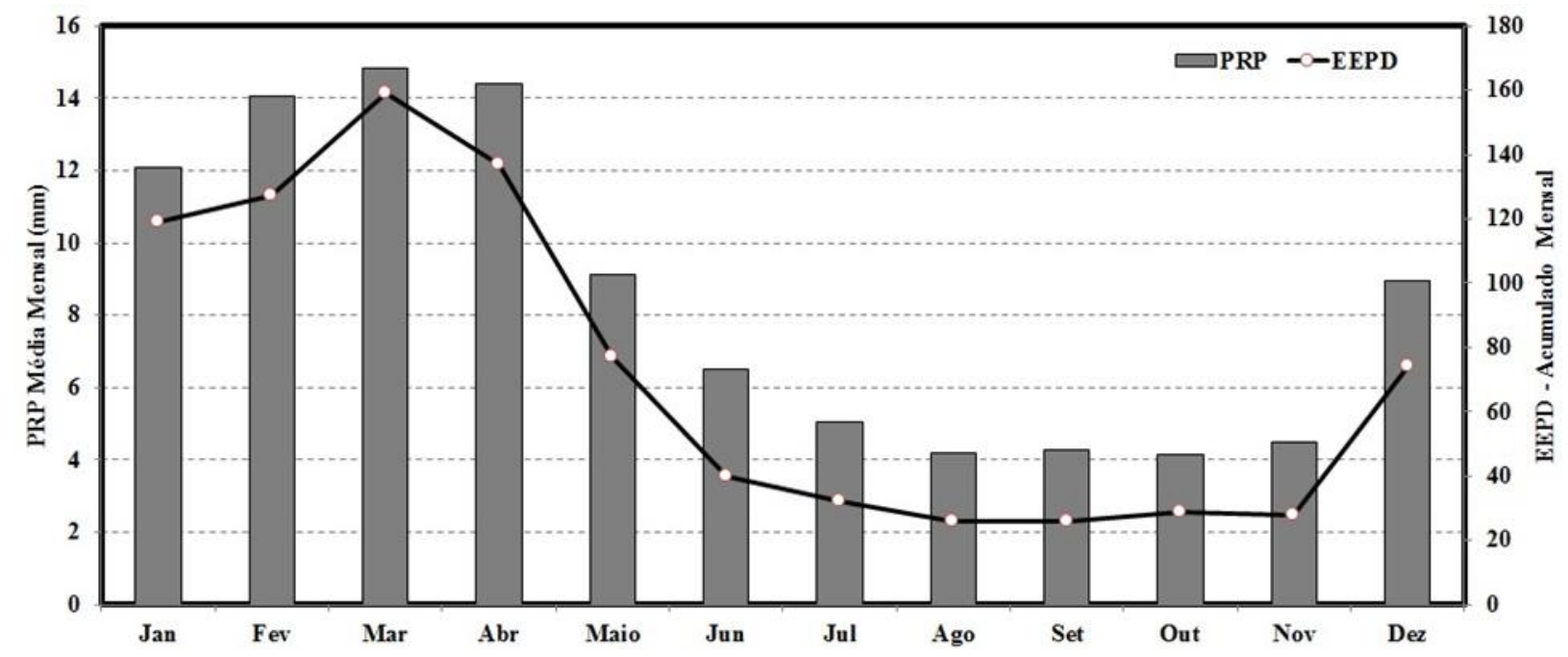

Figura 3. Variabilidade média mensal em $\mathrm{mm} \mathrm{dia}^{-1}$ (barra) e número de casos mensais de EEPD (linha) entre 1987 a 2009.

\subsection{Caracterização dos tipos de consequências e dos principais bairros afetados pelos EEPD na cidade de Belém-Pará}

A Figura 4 apresenta uma análise de regressão linear simples entre o total mensal de EEPD e o total mensal das notícias publicadas para os anos de 1987 a 2009. Esta regressão exibe uma alta correlação $\left(\mathrm{R}^{2}=0,99\right)$ entre o acumulado mensal de EEPD e de notícias publicadas, indicando que o limiar de $24 \mathrm{~mm}$ que classifica EEPD está associado a falta de infraestrutura da cidade em receber chuvas, haja visto que os impactos das chuvas a partir de $24 \mathrm{~mm}$ estão bem correlacionados com as notícias dos jornais. Os jornais evidenciam um 'acontecimento infeliz' (causal ou não) do qual resulta o dano, estrago, avaria, destruição, perdas humanas, chegando até o desastre (Monteiro, 1991). Ressalta-se que a variabilidade interanual e mensal da quantidade de notícias, que foram publicadas em consequência dos EEPD, estão diretamente associadas aos anos de maiores volumes pluviométricos (Figura 2 e 3).

As principais consequências que os EEPD geraram à cidade e/ou sociedade, publicadas nos jornais da cidade de Belém no período de 1987 a 2009, são apresentadas na Figura 5. Os alagamentos representam $65 \%$ das notícias que foram divulgadas na imprensa (Figura 5 - painel à direita), com os máximos nos anos 1988, 2008 e 2009 (Figura 5 - painel à esquerda). O congestionamento no trânsito representa $15 \%$ das notícias (Figura 5 - painel à direita), sendo considerado a segunda maior consequência que ocorre na cidade.

A cidade de Belém representa a experiência de maior adensamento urbano em toda a região amazônica. Comportam aproximadamente 3 milhões de habitantes, o que foi considerada uma das maiores taxa de ocupação humana na Amazônia (Castro, 2003). Logo, o quadro de ocupação urbana intensa e desordenada, junto com as condições de terrenos 
alagadiços da cidade, faz com que, em qualquer período, uma precipitação extrema provoque sérios problemas a população. Além disso, o processo de urbanização impermeabiliza o solo proporcionando o aumento dos problemas relacionados ao alagamento da cidade. Então, toda vez que acontece uma chuva de intensidade moderada a forte, grande parte da cidade fica alagada devido à falta de uma rede pública de esgoto sanitário adequada. O percentual de domicílios que utilizam rede de esgoto em Belém sofreu redução entre 2001 a 2006. Em 2001, $13 \%$ dos domicílios eram servidos pela rede de esgoto, enquanto em 2006 essa proporção caiu para apenas 9\%. A redução decorreu do aumento do número de domicílios e da desativação de redes antigas. Além disso, os municípios de Marituba, Benevides e Santa Bárbara não possuem rede pública de esgoto (Leão et al., 2008).

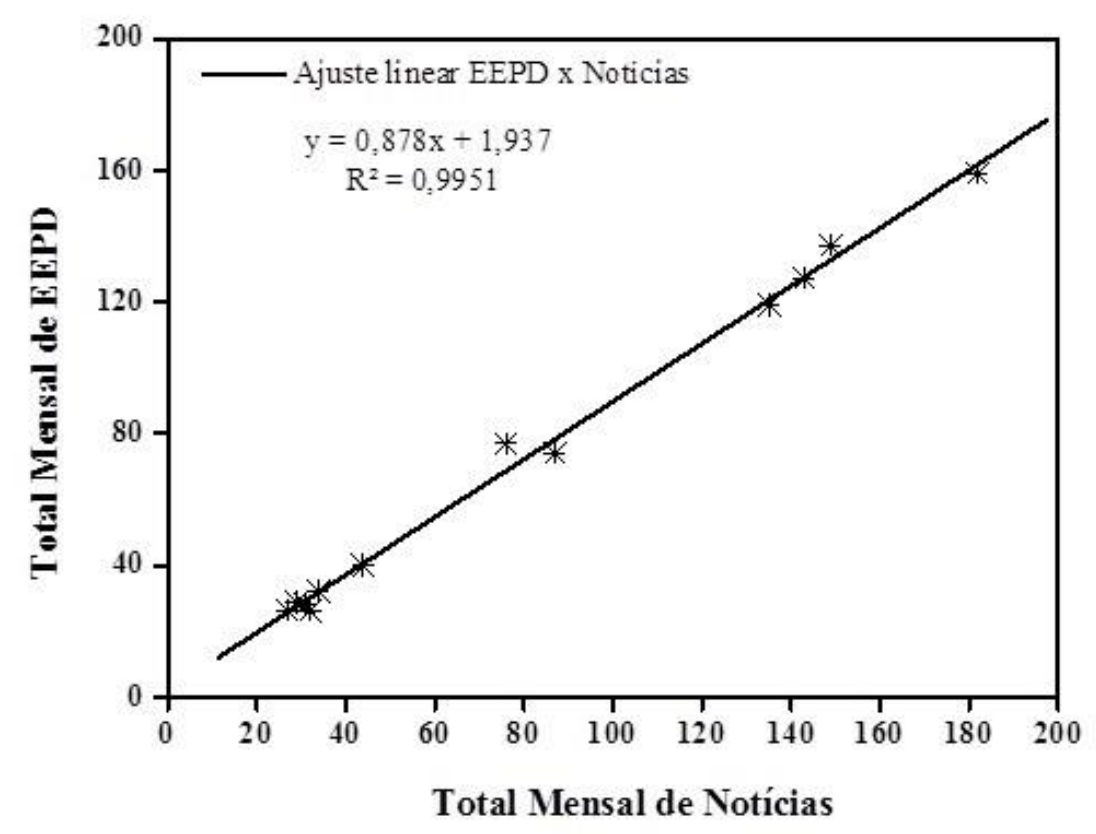

Figura 4. Regressão linear simples entre o acumulado mensal de EEPD e das notícias publicadas nos jornais durante os anos de 1987 a 2009.

Uma particularidade significativa da cidade é a sua arborização composta por diversos túneis de mangueiras seculares, que resistem ao passar do tempo e são elementos presentes nos espaços públicos. As quedas de árvores representam $12 \%$ das principais consequências (Figura 5 - painel à direita) e ocorrem devido os ventos de intensidade moderado/forte. A maioria das nuvens formadas em Belém é do tipo Cumuloninbus de grande desenvolvimento vertical, caracterizadas por gerar ventos fortes, chuvas duram até 2 horas. Precipitações desse tipo causam muitos transtornos, chegando em alguns casos a provocar interrupção de energia, devido ao desligamento de transmissão e queda de raios. Os ventos moderado-fortes também ocasionam destelhamentos e queda de placas; este tipo de consequência representa $5 \%$ das notícias (Figura 5 - painel à direita).

As descargas atmosféricas são intensas descargas elétricas que ocorrem na atmosfera em um curto intervalo de tempo, realizando um percurso de alguns quilômetros. Essas descargas elétricas podem ocorrer associadas às explosões nucleares, erupções vulcânicas e tornados. Contudo, geralmente, se originam em nuvens do tipo Cumulonimbus, ou seja, nuvens de tempestades (Uman, 1987). As descargas atmosféricas representam 3\% das notícias (Figura 5 - painel à direita). 


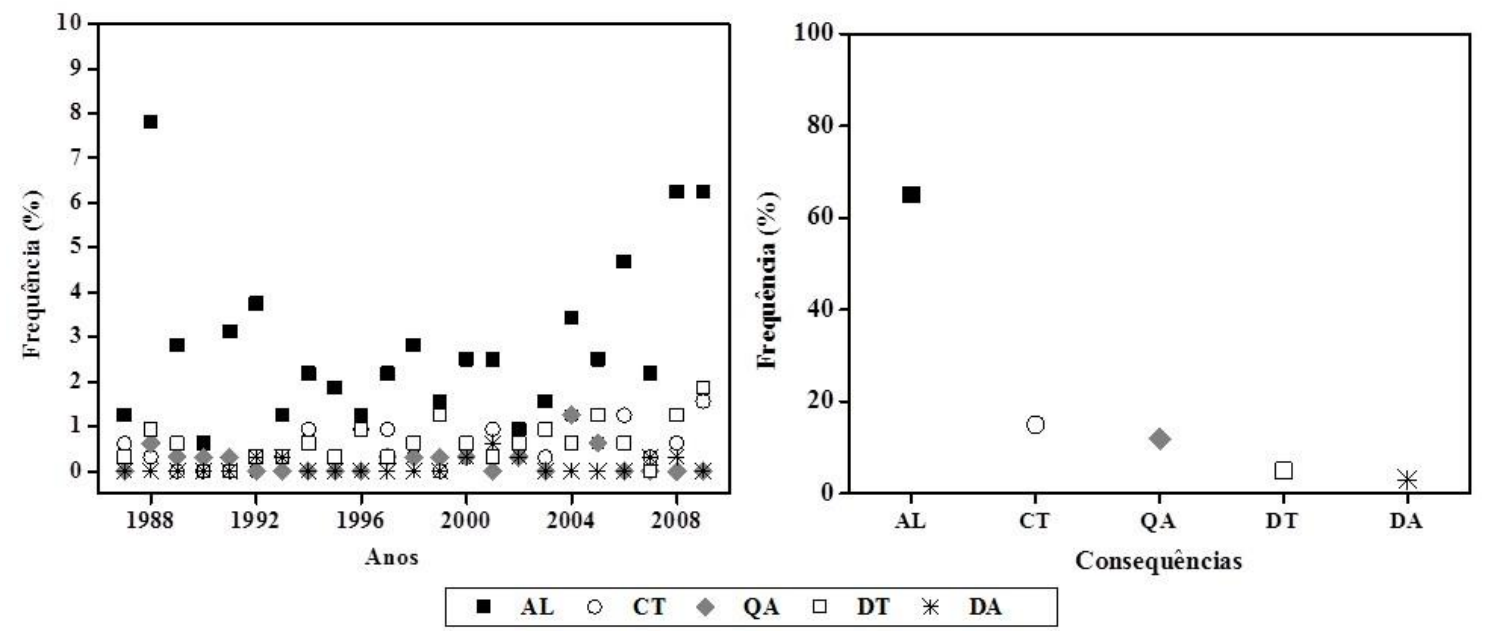

Figura 5. Principais consequências que os EEPD geraram à cidade e/ou à sociedade de Belém.Pará nos anos de 1987 a 2009. O painel à esquerda exibe a frequência interanual da consequência dos EEPD e o painel à direita apresenta a frequência do total de casos da consequência dos EEPD para o período em estudo. AL (alagamento); CT (congestionamento no trânsito); QA (queda de árvores); DT (destelhamentos); DA (descargas atmosféricas).

Os principais bairros afetados por alagamentos foram Cremação, Jurunas, Batista Campos, Pedreira, Guamá, Marco e Campina (Figura 6). Os três bairros mais afetados (Cremação, Jurunas, Batista Campos) estão localizados um ao lado do outro (Figura 7) e a bacia hidrográfica da Travessa Quintino Bocaiúva estende-se entre eles. Santos (2010) estudou esta bacia e constatou que o índice de drenagem é de aproximadamente $0,71 \mathrm{~km} / \mathrm{km}^{2}$, o qual é considerado muito baixo segundo a classificação de Sthraler (1957), tornando esta bacia muito suscetível a alagamentos e inundações. $\mathrm{O}$ autor ainda evidencia o fato de que a maior parte da topografia da bacia apresenta baixa declividade, onde 53,97\% da área apresenta declividade abaixo de $0,5 \%$, dificultando o escoamento da água e favorecendo a formação de pontos de alagamentos.

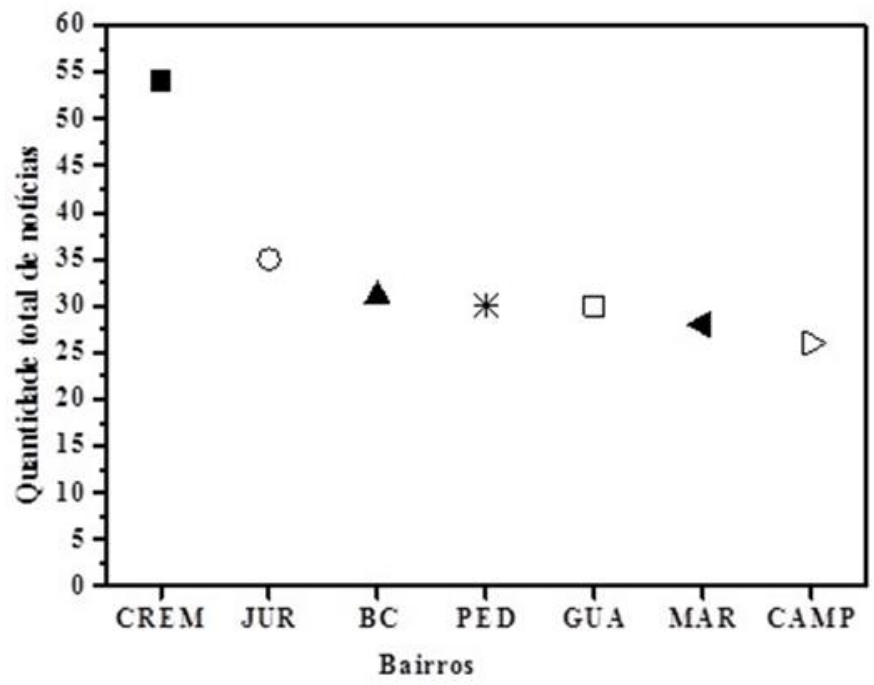

- CREM O JUR $\triangle B C$ * PED $\square$ GUA \ MAR $D$ CAMP

Figura 6. Bairros que mais apresentaram notícias em consequência dos EEPD na cidade de Belém-Pará nos anos de 1987 a 2009. CREM (Cremação); JUR (Jurunas); BC (Batista Campos); PED (Pedreira); GUA (Guamá); MAR (Marco); CAMP (Campina). 


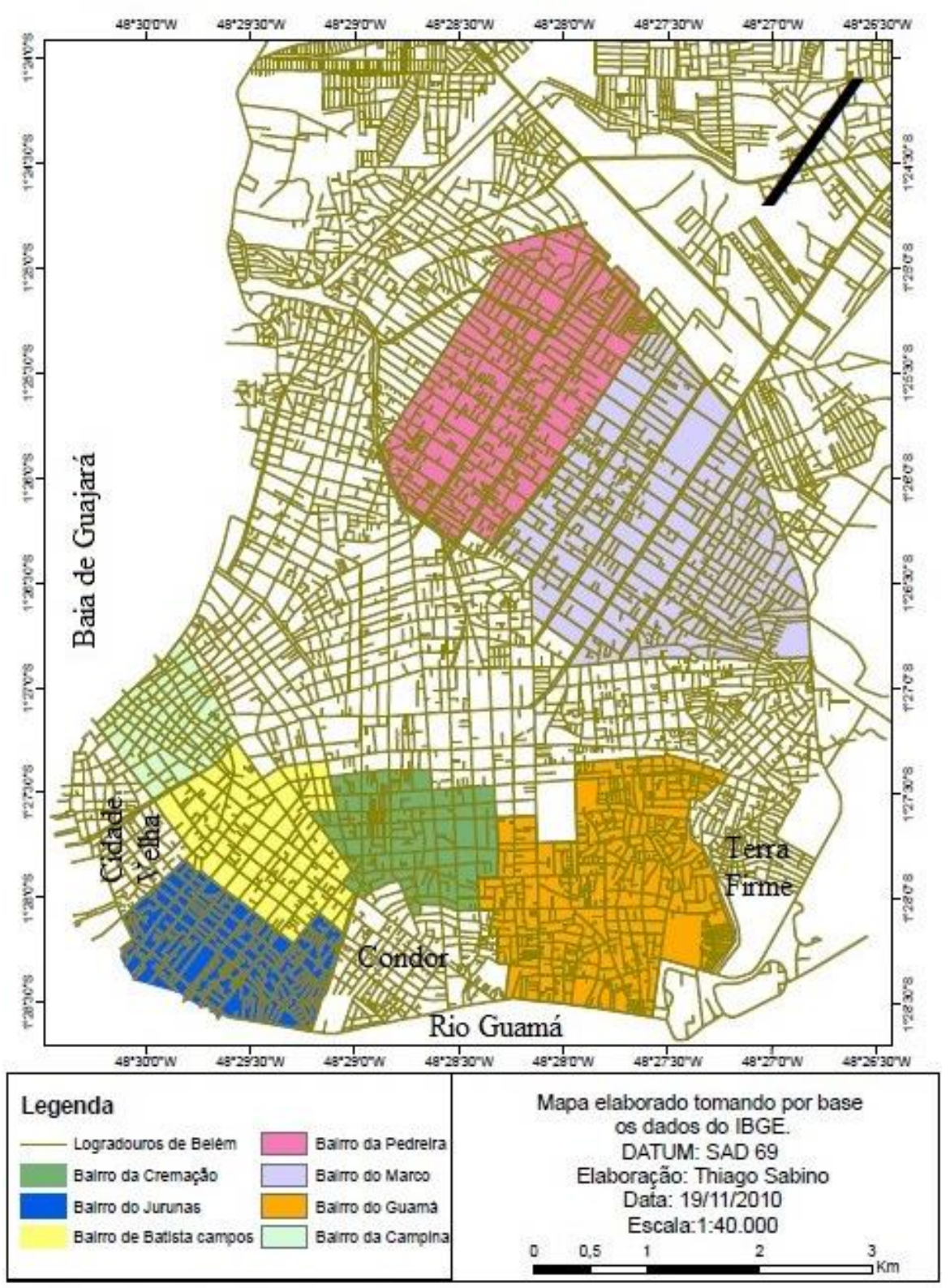

Figura 7. Localização dos principais bairros afetados por pontos alagamentos.

O bairro da Cremação foi o que mais sofreu com os eventos extremos de precipitação (54 notícias/Figura 6). Este bairro possui vários canais e mesmo que a chuva não seja muito forte, causa prejuízos à sociedade, como exemplifica as notícias dos dias 4 de Dezembro de 2009 e 1 de Abril de 2009 (ver com maiores detalhes na Tabela 1). O segundo bairro mais prejudicado foi o bairro do Jurunas (35 notícias/Figura 6), pois, além deste possuir canais, ele está localizado na Região costeira do rio Guamá e o transporte de umidade em direção ao bairro favorece ainda mais os eventos extremos (verificar notícia do dia 28 de Fevereiro de 1991 na Tabela 1). O bairro da Batista Campos, que faz fronteira com Jurunas e Cremação, é o terceiro com maior quantidade de notícias sobre o alagamento (31 notícias/Figura 6), apesar de ser um bairro nobre da cidade de Belém. Neste bairro ocorrem alagamentos nas ruas e casas próximas ao canal localizado na Rua Quintino Bocaiúva, como mostra a notícia do dia 28 de Abril de 1998 (Tabela 1).

Os bairros da Pedreira e do Guamá sofrem com alagamentos devido à falta de tratamento adequado do esgoto, nestes bairros foram reportados 30 notícias cada (Figura 6), como 
mostram as reportagens dos dias 26 de Março de 1987 e 3 de Dezembro de 2007, vide na Tabela 1.

O bairro do Marco foi o quinto que mais sofreu com alagamentos (28 notícias/Figura 6), este fica vizinho ao bairro da Pedreira (semelhante aos três bairros, Cremação, Batista Campos e Jurunas, que também são vizinhos). Neste bairro há o canal Visconde de Inhaúma que ao transbordar prejudica os moradores, como mostra a notícia do dia 25 de Abril de 2005 (Tabela 1).

Por último, o bairro de Campinas foi o sexto bairro a sofrer com alagamentos (26 notícias/Figura 6). Este bairro se localiza na Região costeira da Baía do Guajará. SANTOS (2010) indicou que existe uma ação potencializada quando coincide ocorrência dos eventos pluviométricos intensos com a maré alta do Rio Guamá. Salienta-se ainda que neste bairro ocorreram graves alagamentos, porém não com tanta frequência, pois o problema maior se dá ao coincidir chuva forte com a maré alta do rio. Os alagamentos ocorrem principalmente no mercado do Ver-o-Peso, como mostra a notícia de 10 de Março de 2001 (Tabela 1).

Tabela 1. Principais publicações de notícias nos jornais da cidade de Belém durante os anos de 1987 a 2009.

\begin{tabular}{|c|c|c|}
\hline DIAS & PRP & NOTÍCIAS \\
\hline $26 / 03 / 1987$ & $71,8 \mathrm{~mm}$ & $\begin{array}{l}\text { "Na travessa Estrela, bairro da Pedreira, os moradores passaram a } \\
\text { madrugada ilhados em suas próprias casas." } \\
\text { Fonte: Chuva caiu sem... (1987). }\end{array}$ \\
\hline $28 / 02 / 1991$ & $48,2 \mathrm{~mm}$ & $\begin{array}{l}\text { "Os moradores da Dr. Moraes entraram em pânico com esgotos } \\
\text { entupidos devido as fortes chuva." } \\
\text { Fonte: Queixas (1991). }\end{array}$ \\
\hline $28 / 04 / 1998$ & $126,8 \mathrm{~mm}$ & $\begin{array}{l}\text { "A Rua Fernando Guilhon apresentou grande quantidade de lama } \\
\text { pela falta de drenagem dos canais." } \\
\text { Fonte: Periferia submerge com... (1998). }\end{array}$ \\
\hline $10 / 03 / 2001$ & $31,8 \mathrm{~mm}$ & $\begin{array}{l}\text { "Baía do Guajará transbordou e águas de } 3,5 \text { metros invadiram casas } \\
\text { comerciais nas avenidas Marechal Hermes, Castilho de França e } \\
\text { Ver-o-Peso." } \\
\text { Fonte: São as águas... (2001). }\end{array}$ \\
\hline $25 / 04 / 2005$ & $183,3 \mathrm{~mm}$ & $\begin{array}{l}\text { "Eletrodomésticos boiaram no bairro do Marco, os moradores da } \\
\text { Visconde de Inhaúma entre Mauriti e Barão do Triunfo fizeram } \\
\text { protesto, pois sete casas foram alagadas." } \\
\text { Fonte: Chuva alaga cidade... (2005). }\end{array}$ \\
\hline $03 / 12 / 2007$ & $73,7 \mathrm{~mm}$ & $\begin{array}{l}\text { "Na Avenida Conselheiro Furtado, bairro do Guamá, a água que } \\
\text { cobriu completamente a via, invadiu várias casas, deixando muitas } \\
\text { famílias ilhadas." } \\
\text { Fonte: Dias (2007). }\end{array}$ \\
\hline $01 / 04 / 2009$ & $53,6 \mathrm{~mm}$ & $\begin{array}{l}\text { "O canal transbordou, ocasionando alagamento acima do normal na } \\
\text { Rua dos Pariquis, o nível da água subiu tanto que chegou à altura do } \\
\text { pescoço de alguns moradores." } \\
\text { Fonte: Noguchi (2009). }\end{array}$ \\
\hline $04 / 12 / 2009$ & $22,6 \mathrm{~mm}$ & $\begin{array}{l}\text { "Chuva durou pouco tempo, mas foi o suficiente para alagar várias } \\
\text { ruas e casas. O bairro da Cremação foi um dos mais afetados." } \\
\text { Fonte: Noguchi (2009). }\end{array}$ \\
\hline
\end{tabular}




\section{CONCLUSÕES}

Os impactos dos eventos extremos de precipitação diária na cidade de Belém-Pará foram estudados com base em notícias de jornais no período de 1987 a 2009. Notou-se que a maioria dos EEPD geraram problemas para a cidade e viraram notícias nos jornais.

As notícias indicaram que os EEPD causaram desastres físicos, econômicos e sociais devido à falta de infraestrutura da cidade, ocupação urbana desordenada, impermeabilização do solo e falta de rede de esgoto adequada. Isto foi evidenciado, pois a principal consequência que os EEPD ocasionaram a cidade foi o alagamento. Os bairros localizados na bacia hidrográfica da Travessa Quintino Bocaiúva são os que mais ficam alagados, pois observa-se que o canal da Quintino Bocaiúva ainda sofre influência da maré alta do rio Guamá e quando chove, a vazão do escoamento superficial do canal é prejudicada.

As publicações dos jornais mostraram que os congestionamentos do trânsito, as quedas de árvores, os destelhamentos e as descargas atmosféricas também ocorreram na cidade, principalmente devido às nuvens de chuva que são formadas na cidade (cumulonimbus) com grande desenvolvimento vertical, altamente eletrificada, e associada a ventos fortes.

Portanto, a cidade necessita com urgência de um gerenciamento ambiental, principalmente devido ao crescimento exponencial da população e as necessidades de serviços urbanos. Pois apesar da precipitação anual na cidade ser em média $3000 \mathrm{~mm}$ com máximo de $3900 \mathrm{~mm}$, ela não possui rede de drenagem (esgoto) adequada o que provoca todo o problema de alagamento da cidade, agravada pela falta de educação ambiental da população.

Outro fato é a importância das notícias registradas nos veículos de comunicações. A partir das últimas décadas do século XX começou a haver um debate acerca do uso de jornais como fontes de pesquisa e no Brasil alguns trabalhos científicos foram elaborados com base no acervo dos impressos. Desta forma, as notícias dos jornais mostram sua importância dentro da sociedade, servindo, como nesta pesquisa, de fonte fundamental para um estudo mais detalhado sobre as consequências dos EEPD na cidade de Belém - Pará.

\section{AGRADECIMENTOS}

Os autores agradecem a Financiadora de Estudos e Projetos (FINEP) pelo apoio financeiro ao Projeto Rede de Monitoramento e Pesquisa de Fenômenos Meteorológicos Extremos da Amazônia - 1a e $2^{\mathrm{a}}$ fase. Thamiris L. de O. Brandão Campos agradece ao Conselho Nacional de Desenvolvimento Científico e Tecnológico (CNPq), a Universidade Federal do Pará pela Bolsa PIBIC concedida e ao Thiago Sabino pela elaboração do mapa utilizado.

\section{REFERÊNCIAS}

BRYANT, L.; CARVER, L.; BUTLER, C. D.; ANAGE, A. Climate change and family planning: least-developed countries define the agenda. Bulletin of the World Health Organization, v. $87, \quad$ p. $852-857, \quad 2009 . \quad$ http://dx.doi.org/10.1590/S004296862009001100014

CASTRO, E. Geopolítica da água e novos dilemas a propósito da Amazônia e seus recursos naturais. In: ARAGON L. E.; CLÜSENER-GODT, M. (Orgs.) Problemática do uso local e global da água da Amazônia. Belém: NAEA, 2003. p. 334.

CHU, P. S.; ZHAO, X.; RUAN, Y.; GRUBBS, B. Extreme rainfall events in the Hawaiian Islands. Journal of Applied Meteorology and Climatology, v. 48, p. 502-516, Jul. 2009. http://dx.doi.org/10.1175/2008JAMC1829.1 
CHUVA alaga cidade e traz muitos problemas. O Liberal, Belém, 25 abr. 2005. Cidades, p. 4.

CHUVA caiu sem qualquer trégua. O Liberal, Belém, 27 mar. 1987. Cidades, p. 08.

COHEN, J.; SILVA DIAS, M. A. F.; NOBRE, C. A. Environmental conditions associated with Amazonian squall lines: A case study. Monthly Weather Review, v. 123, p. 31633174, 1995. http://dx.doi.org/10.1175/1520-0493(1995)123\%3C3163:ECAWAS\% 3E2.0.CO;2

DE SOUZA, E. B.; AMBRIZZI, T. Modulation of the intraseasonal rainfall over tropical Brazil by the Madden-Julian oscillation. International Journal of Climatology. São Paulo, v. 26, p. 1759-1776, 2006. http://dx.doi.org/10.1002/joc.1331

DIAS, D. Canais transbordam e trânsito fica lento. O Liberal, Belém, 3 dez. 2007. Cidades, p. A10.

GRIMM, A. M. Interannual climate variability in South America: impacts on seasonal precipitation, extreme events, and possible effects of climate change. Stochastic Environmental Research and Risk Assesment, v. 25, p. 537-554, 2011. http://dx.doi.org/10.1007/s00477-010-0420-1

INSTITUTO NACIONAL DE METEOROLOGIA - INMET. Normais climatológicas 1961 a 1990. Brasília, DF, 1992.

LEÃO, N.; ALENCAR, C.; VERÍSSIMO, A. Belém sustentável 2007. Belém: Instituto do Homem e Meio Ambiente da Amazônia, 2008. 140 p.

MALONE, T. F. Compendium of meteorology. Washington: American Meteorological Society, 1951. p. 1334.

MARENGO, J. A; NOBRE, C. A. The hydroclimatological frame work of Amazonia. In: RICHEY, J.; MAC CLAINE, M.; VICTORIA, R. (Orgs.). Biogeochemistry of Amazonia. New York: Cambridge University Press, 2000.

MARENGO, J. A. Impactos de extremos relacionados com o tempo e o clima - Impactos sociais e econômicos. Boletim do Grupo de Pesquisa em Mudanças Climáticas GPMC, Edição Especial, 2009.

MONTEIRO, C. A. de F. Clima e excepcionalismo: conjecturas sobre o desempenho da atmosfera como fenômeno geográfico Florianópolis: Ed. UFSC, 1991. 241 p.

NOGUCHI, M. Chuva de uma hora causa novos alagamentos. Diário do Pará, Belém, 04 dez. 2009. Belém, p. A6.

PERIFERIA submerge com a chuva. O Liberal, Belém, 28 abr. 1998. Atualidades.

QUEIXAS. O Liberal, Belém, 28 fev. 1991. Cidades, p. 08.

SANTOS, F. A. A. Alagamento e inundação urbana: modelo experimental de avaliação de risco. 2010. 165f. Dissertação (Mestrado em Ciências Ambientais)-Universidade Federal do Pará/Museu Paraense Emílio Goeldi/Embrapa, Belém, 2010.

SÃO as águas de março. O Liberal, Belém, 10 mar. 2001. Cidade, p. 10.

SILVA, K. Capital do Pará: Belém. Disponível em:

<http://www.amazonia.com.br/turismo_novo/para/belem2.asp>. Acesso em: 27 fev. 2008. 
SIMIELLI, M. E. Geoatlas. São Paulo: Ática, 1991.

SOUZA, E. B.; NOBREGA, P. Uma revisão sobre o padrão de dipolo no Atlântico Tropical. Revista Brasileira de Meteorologia, v. 13, n. 3, p. 1-44, 1998

STHRALER, A. N. Quantitative analysis of watershed geomorphology. Transactions, American Geophysical Union, v. 38, p. 913-920, 1957.

TRUONG, N. M.; TIEN, T. T.; ROGER A. PIELKE SR.; CASTRO, C. L.; LEONCINI, G. A modified Kain-Fritsch scheme and its application for the simulation of an extreme precipitation event in Vietnam. Monthly Weather Review, v. 137, p. 766-789, 2009. http://dx.doi.org/10.1175/2008MWR2434.1

UMAN, M. A. The lightning discharge. Orlando: Academic Press, 1987. 370 p.

WILKS, D. S. Statistical methods in the atmospheric sciences. 2. ed. San Diego: Elsevier Science \& Technology Books, 2006.

XAVIER, T. M.; XAVIER, A. F. S.; ALVES, J. M. B. Quantis e eventos extremos aplicações em ciências da terra e ambientais. Fortaleza: RDS; Livro Técnico, 2007. $278 \mathrm{p}$. 